\title{
6.3 The growth of social confidence in the economic sphere in connection with the stated pandemic situation all over the world
}

A necessary condition for the viability of the political system and the most important aspect of civil society is trust, the existence of trust as a socio-cultural phenomenon, this is well argued "a solidary community of citizens, who take part in politics and are loyal to the government, bound by strong bonds, could not exist without horizontal trust, as citizens mutually bestow each other, as well as vertical trust in public institutions "[254].

Taking this circumstance into account, it can be concluded that the problem of citizens' trust in civil servants gains the status of one of the most important in both the political and socio-economic life of society in any country. Also, because the objects of special attention from society are civil servants in various directions of development of state systems focused on the development of capitalism, socialism or even a totalitarian system, the level of public confidence in these systems and officials representing them through their activities determines the the highest degree of social stability of society (subject to high indicators, the above-mentioned index) and its readiness for serious actions, collectively aimed at improving the quality of life of the population of the countries, reforms.

A high level of trust, which is manifested by the population in relation to the state and to civil servants, as representatives of it, also contributes to a stable socio-political situation, increases the level of interaction between state structures and civil society, has a positive effect on the quality of work of the state apparatus and, in general, becomes the basis for the formation of a favorable climate of trusting relationships in society. However, the civil service is considered the most important element of transformations in such spheres of the state's life as: power, economy, social sphere, in the sphere of national security, according to many experts, today it is not adapted and is not able to solve many strategic tasks. One of the problems, which can be called one of the key ones, regarding the functioning of the modern state, the state apparatus is that the interaction of the state and society, at the moment, does not meet the social 
needs of citizens, today there are no mechanisms on the part of the civil society of the social control over the activities of public authorities, which can and does lead to both the spread of corruption and abuse in the public service.

As a result, in the last decade in many countries there has been, with varying degrees of intensity, a significant drop in the level of trust on the part of the population in relation to the authorities. This fact is due to the growing and continuing to grow demand on the part of society for the efficiency of the work of the state and civil servants, as its representatives, for the quality of services they provide, and most importantly, for their moral character, when we talk about intolerance in relation to immoral acts, bureaucracy, corruption. actions, isolation from the interests of the population, etc.

To date, a variety of approaches have been developed for trust research. As separate scientific directions, those that study trust, both some components of public and political consciousness, and, to a large extent, its influence, can be distinguished. Many scientific studies, this indicator, which affects the economy (V.P. Zinchenko, A.V. Belyanin, V.E.Bodyul, I.K. Vladykina and S.N. Plesovskikh, D.M.Dankin, V.V. P. Goryainov, V. N. Dakhin, K. F. Zachinsky, A. V. Komina, G. L. Kertman, Yu. N. Kopylova, Yu. V. Levada, D. W. Lovell, N. N. Lobanov, V.N. Lukin, V.N. Minina, B.Z. Milner, T.M. Mozgovaya, V.A.Miroshnichenko, D.V. Olshansky, G.U. Soldatova, T.P. Skripkina, N.Yu. Tishkova, N.N. Yamko and many others). Namely, the works of D.M. Dankin. As the subject of analysis, Yu.N. Kopylova advocates the confidence of the population and is considered as a factor in increasing the social status of the authorities in the state. According to the research of A.V. Comina analyzes such factors as responsibility, authority, trust in the role of imperatives of power. In relation to the institutions of state power and management, the factors of mistrust were studied by V.N. Minina. Trust and distrust as a social and social problem are considered by T. Govir, Yu.A. Levada, T.A. Pravorotova, A.B. Ruzanov and others. Foreign studies are also devoted to the problem of political and public trust (P. Brown, D. Lewis and A. Weigert, J. Capella and K. Jamison, D. Carnevale, S. Mitchell, K. Parks and S. Comorita, A. Seligman, F. Fukuyama, M. Hezirington, R. Abramson, etc.). To assess 
the level of trust today, both foreign and Russian researchers have developed and widely used "one-dimensional" trust indices. For example, in 2008, the Levada Center created an updated methodology for calculating the Index of Social Sentiments, in accordance with which assessments of the level of public confidence in basic government institutions began to be taken into account. The TI trust index is calculated as the sum of the percentage of those who "fully trust" T, Half of those who "partially trust" NT gk.c 100:

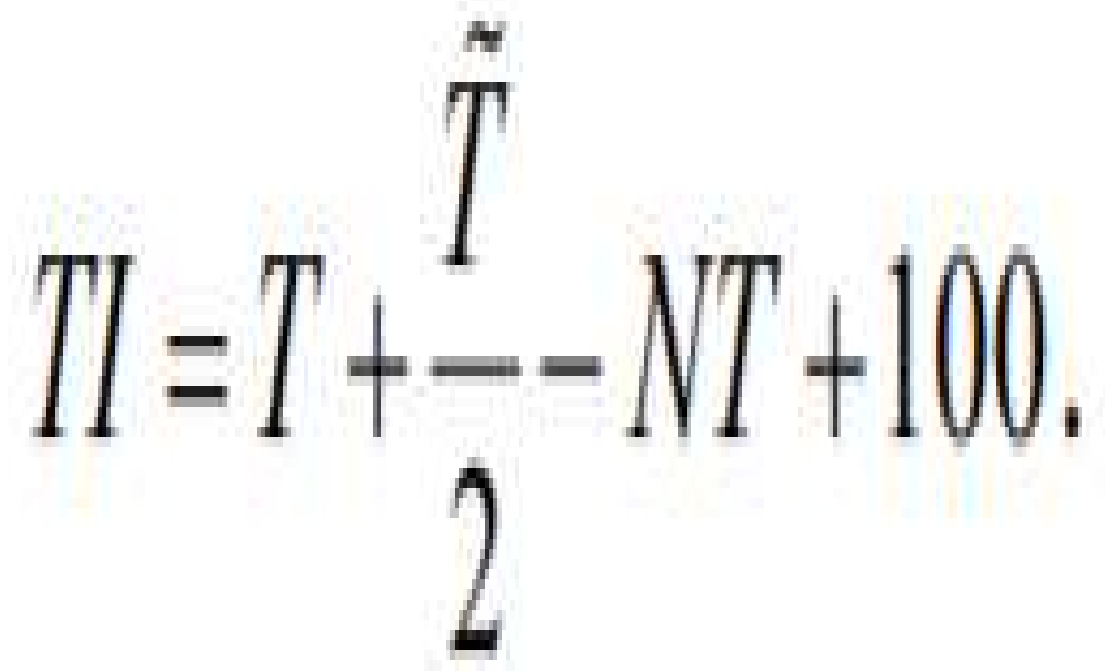

[256].

Tracking the sentiments of citizens regarding trust in the instruments of power, as its embodiment, is a very interesting and informative process.

According to the data provided by the portal of the electronic edition "NONEWS", which can be seen in more detail in Table 6.3.1, the confidence index varies significantly from country to country. The World Economic Forum annually, in its large report, The Global Competitiveness Report, includes a separate study that examines the level of citizens' trust in politicians in the country. Based on the results of the study, a list of countries is compiled by the level of public trust in politicians. [255]

Table 6.3.1.

Confidence index by countries of the world

\begin{tabular}{|l|l|l|}
\hline № & Country & Index \\
\hline 1. & Singapore & 6.4 \\
\hline 2. & UAE & 6.3 \\
\hline 3. & New Zealand & 6.1 \\
\hline
\end{tabular}




\begin{tabular}{|l|l|l|}
\hline 4 & Qatar & 5.9 \\
\hline 5. & Finland & 5.8 \\
\hline 6. & Norway & 5.7 \\
\hline 7. & Netherlands & 5.6 \\
\hline 8. & Luxembourg & 5.6 \\
\hline 9. & Switzerland & 5.5 \\
\hline 10. & Rwanda & 5.4 \\
\hline 11. & Sweden & 5.2 \\
\hline 12. & Saudi Arabia & 5.2 \\
\hline 13. & Germany & 5.1 \\
\hline 14. & Denmark & 5.1 \\
\hline 15. & Canada & 5.0 \\
\hline 16. & USA & 4.8 \\
\hline 17. & United Kingdom & 4.8 \\
\hline 18. & Hong Kong & 4.8 \\
\hline 19. & Oman & 4.7 \\
\hline 20. & Azerbaijan & 4.7 \\
\hline 21. & Ireland & 4.6 \\
\hline 22. & Australia & 4.6 \\
\hline 23. & Iceland & 4.6 \\
\hline
\end{tabular}

Although many scientists have studied the institution of trust (among them:

Fukuyama F., Kupreychenko V.A., Obosov N.N. and many others), we see that this issue has not been sufficiently studied for many reasons, and one of them is the lack of a simple and accurate way its calculation and its features of manifestation in various spheres of economic, legal, not to mention linguistic (connotations and their influence on mutual understanding between agents of a particular sphere of economic activity and the above.

Along with this, it is worth noting that it is trust, as a marketing and financial tool, that is most often used by companies to attract their customers, and when this idea is widely used to the maximum, primarily by institutions such as banks, security system manufacturers and others (trading companies, any that have social interaction).

The rational approach is based on evidence, calculations, statistics.

The purpose of this study: to establish the existence of an interdependence between the index of the level of trust in power and the economic indicators of countries, or to refute the existence of such a relationship; substantiate the results of the study; suggest possible ways and directions for further research in this area. 
To fulfill the goal set in this study and substantiate the results, we use statistical data and the calculation of the correlation coefficient.

In this study, we take into account only 2 variables, which, of course, can lead to inaccuracies.

Many conduct the research in a one-dimensional way, which obligatory leads to not only inaccuracies, but even absolute mislead in the direction of research. For instance when researching trust as an influential tool for economy we should view not only index of trust from society to the government, but from government to society as well. As this is the two way road. We should view and track the changes and the shift of balance in these to parallel and simultaneous processes to see how this living organism behaves. And we are to admit that both directions of the research and study of trust gives different outcomes because the move in different directions, but at the same time they move towards each other. As there is no other way to interact and enjoy the benefits of it.

In most of the cases these directions of movement are preconditioned with the goals, means of reaching these goals, set of resources and many more. But what make them harmonize their movement and move towards each other is the interconnection and interdependence between these two motions that actually precondition the level of life of this or that country.

And taking into account the above mentioned, facts we can conclude that these motions can be acting synergically with a very strong probability.

In this direction we are going to develop our research and for this aim we will have to take into account many more indices.

Still with the obvious need to involve many more indices we realize the risk that occure when scientist neglect such tool as astrogating.

Below is a table with an array of data, on the basis of which we tried to establish the relationship between the index of confidence in the countries listed in the table in the authorities of these countries and the relationship between the level of gross domestic income per capita in these countries by calculating the correlation coefficient. 
Table 6.3.2.

Correlation coefficient - the degree of interdependence of the index of public confidence in the authorities and the GDP of their countries.

\begin{tabular}{|c|c|c|}
\hline & GDP, USA dollars & Index of trust \\
\hline USA & 20574972485307 & 83,7 \\
\hline China & 22526559322400 & 73,9 \\
\hline Japan & 5231066130915 & 82,3 \\
\hline Germany & 4473821954811 & 81,8 \\
\hline Sweden & 547238102912 & 81,2 \\
\hline Russia & 3968180465310 & 66,7 \\
\hline Hong Kong & 449639702214 & 83,1 \\
\hline Great Britain & 3121120096107 & 81,2 \\
\hline Canada & 1843053386835 & 79,6 \\
\hline France & 3097061752487 & 78,8 \\
\hline Australia & 1262034238485 & 78,7 \\
\hline New Zealand & 210877926824 & 76,7 \\
\hline \multirow[t]{2}{*}{ Israel } & 363597897494 & 76,7 \\
\hline & & $-0,036291995$ \\
\hline
\end{tabular}

So, the correlation coefficient is -0.036291995 , based on the analysis of the data set indicated above in table 1 . What allows us, at first glance, to conclude that these indicators are not at all interconnected, BUT !, what we can really conclude is that with such a rough and abstracted calculation of the correlation coefficient, and therefore the relationship between the investigated factors less than zero.

To talk about more or less reliable conclusions, it is necessary to take into account many more indicators, such as: population, traditions, culture, immigration processes, the specifics of national production, the co-relativity of the resource potential of countries, at least.

Thus, at this stage, we can only conclude that the topic of research is very deep and requires further research. 